\title{
Hemovac blood after total knee arthroplasty as a source of stem cells
}

\author{
Seon Ae Kim ${ }^{1}$, Ho Youn Park ${ }^{1}$, Yong-Woon Shin ${ }^{2}$, Eun Jeong Go ${ }^{1}$, Young Ju Kim ${ }^{3}$, Yoo Chang Kim ${ }^{1}$, \\ Asode Ananthram Shetty ${ }^{4}$, Seok Jung Kim ${ }^{1}$
}

${ }^{1}$ Department of Orthopedic Surgery, College of Medicine, The Catholic University of Korea, Seoul, Republic of Korea; ${ }^{2}$ Department of Orthopaedic Surgery, College of Medicine, The Inje University of Korea, Seoul, Republic of Korea; ${ }^{3}$ Department of Nursing Education \& Administration, Uijeongbu St. Mary's Hospital, The Catholic University of Korea, Seoul, Republic of Korea; ${ }^{4}$ Canterbury Christ Church University, Faculty of Health and Wellbeing, Chatham Maritime, Kent, UK

Contributions: (I) Conception and design: SA Kim, SJ Kim; (II) Administrative support: HY Park; (III) Provision of study materials or patients: EJ Go; (IV) Collection and assembly of data: YC Kim; (V) Data analysis and interpretation: YW Shin, YJ Kim; (VI) Manuscript writing: All authors; (VII) Final approval of manuscript: All authors.

Correspondence to: Seok Jung Kim, MD, PhD, FRCS. Department of Orthopedic Surgery, Uijeongbu St. Mary's Hospital, College of Medicine, The Catholic University of Korea, 271, Cheonbo-ro, Uijeongbu-si, Gyeonggi-do, Republic of Korea. Email: peter@catholic.ac.kr.

Background: With increasing life expectancy, stem cell therapy is receiving increasing attention. However, its application is restricted by ethical concerns. Hence a need exists for design of safe procedures for stem cell procurement. Here, we investigated whether hemovac blood (HVB) is an appropriate stem cell source.

Methods: HVB concentrates (HVBCs) from 20 total knee arthroplasty (TKA) patients and bone marrow aspirate (BMA) concentrates (BMACs) from 15 patients who underwent knee cartilage repair were comparatively evaluated. A bone marrow aspiration needle was inserted into the anterior superior iliac spine. Aspiration was performed using a 50-mL syringe, including $4 \mathrm{~mL}$ of anticoagulant, followed by centrifugation to obtain BMACs. To obtain HVBCs, blood was aspirated from the hemovac immediately after TKA surgery. Different cell types were enumerated. Isolation of BMA and HVB mononuclear cells was performed using density gradient centrifugation. Non-hematopoietic fibroblast colonies were quantified by colony forming unit-fibroblast assay surface marker analysis of HVB, HVBC, BMA, and BMAC was performed via flow cytometry. Mesenchymal stem cells (MSCs) isolated from HVBCs and BMACs were examined for osteogenic, adipogenic, and chondrogenic differentiation potential. Gene expression analysis was performed by quantitative real-time polymerase chain reaction (qRT-PCR).

Results: The number of cells from HVB and HVBC was significantly lower than from BMA and BMAC; however, the number of colonies in HVBC and BMAC did not differ significantly $(\mathrm{P}>0.05)$. Isolated cells from both sources had a fibroblast-like appearance, adhered to culture flasks, and formed colonies. Under different culture conditions, MSC-specific surface markers (CD29, CD44, CD90, CD105), osteogenic markers [RUNX2, osteopontin, osteocalcin, and alkaline phosphatase (ALP)] and adipogenic markers (PPAR $\gamma$ and $\mathrm{C} / \mathrm{EBP} \alpha$ ) were expressed. Moreover, SOX9, type II collagen, and aggrecan were significantly upregulated upon chondrogenic differentiation.

Conclusions: HVB from TKA patients is a useful source of stem cells for research.

Keywords: Bone marrow; bone marrow aspirate concentrate (BMAC); hemovac blood (HVB); total knee arthroplasty (TKA); stem cell

Submitted Feb 24, 2020. Accepted for publication Sep 04, 2020.

doi: $10.21037 /$ atm-20-2215

View this article at: http://dx.doi.org/10.21037/atm-20-2215 


\section{Introduction}

Active and continuous efforts have been undertaken in various fields to improve the quality of life as life expectancy has risen significantly over the years. Especially in the medical field, stem cell research is actively progressing in an effort to overcome intractable diseases and maintain quality health during an individual's lifetime $(1,2)$. For stem cell research, diverse tissues, such as umbilical cord blood, bone marrow (3), adipose tissue (4), muscle, teeth (5), cartilage, and synovium are being used as stem cell sources (6-8). Although stem cells from animal tissues can be used for research, their importance and value are lower than those from human tissues. Recently, due to ethical misconduct, reckless stem cell research has been prohibited, and strict regulatory guidelines have been reinforced by the Institutional Review Boards (IRBs) to protect patient rights. Therefore, it would not be possible to receive approval from an IRB or ethics committee if the research is found to be counterintuitive to the patients' interests.

Total knee arthroplasty (TKA) is the gold standard for end-stage osteoarthritis, and a large number of TKA surgeries are performed each year $(9,10)$. Blood collects inside the joint after surgery, and hence, a hemovac line is placed inside the joint post-surgery to decompress the joint, controlling pain and swelling (11-13). A hemovac drain can collect a sufficient quantity of blood to provide adequate numbers of cells. Since the blood is from both the damaged tissue and the bone cutting site, the bone marrow components are included in the hemovac blood (HVB). During a TKA surgery, cutting the surface of cancellous bones including the distal femur or proximal tibia often results in bone marrow leaking from the cut surface. Within the bone marrow aspirate (BMA), a fair amount of venous blood is also often included. Since the stromal component of bone marrow can be used to treat musculoskeletal diseases, such as nonunion fractures or cartilage defects, centrifugation and concentration of the stromal component is often performed to allow for effective clinical treatment. Similarly, HVB can also include bone marrow components; however, the amount of stromal blood is often much less than what is observed in BMAs. As such, a concentration procedure is often necessary. Hence, this study was undertaken to investigate if $\mathrm{HVB}$ can be manipulated in such a way to render it a useful source of stem cells for research.

We present the following article in accordance with the MDAR checklist (available at http://dx.doi.org/10.21037/ atm-20-2215).

\section{Methods}

\section{Patients}

The HVB of 20 patients who underwent TKA was used for this study. The average age of the patients was 72.9 years [range, 57-86 years; standard deviation (SD), 7.56]. BMAs from 15 patients who underwent the arthroscopic cartilage repair procedure were concentrated, and the samples remaining after the procedure were used for comparative analysis. The average age of these patients was 72.1 years (range, 61-80 years; SD, 5.18). The study was conducted in accordance with the Declaration of Helsinki (as revised in 2013). The study was approved by the Institutional Review Board (UC18DESI0056) and informed consent was obtained from each patient.

\section{Bone marrow aspiration and concentration}

Bone marrow aspirate concentrate (BMAC) was obtained by inserting a bone marrow aspiration needle (SPASY ${ }^{\mathrm{TM}}$, Seoul, Korea) into the anterior superior iliac spine after sterilization under general anesthesia. Aspiration was then performed using a $50-\mathrm{mL}$ syringe, including $4 \mathrm{~mL}$ of the anticoagulant citrate dextrose solution (Huons ACD Injection, Huons, Seongnam, Korea), after which $40 \mathrm{~mL}$ of BMA, including $4 \mathrm{~mL}$ of ACD solution, was transferred to a BMC kit (Revmed, Seongnam, Korea). Two cycles of centrifugation were performed to obtain the BMAC. The first cycle was for $6 \mathrm{~min}$ at $2,700 \times \mathrm{g}$, followed by a second cycle for $5 \mathrm{~min}$ at $2,400 \times \mathrm{g}$ (Figure 1$)$.

\section{HVB aspiration and concentration}

Blood (40 mL), including $4 \mathrm{~mL}$ of ACD solution, was aspirated from the hemovac immediately after TKA surgery. The aspirated blood was transferred to the kit (BMC kit ${ }^{\mathrm{TM}}$, Revmed, Seongnam, Korea), and two cycles of centrifugation were performed to obtain the HVB concentrate (HVBC) (Figure 1).

\section{$B M A C$ and $H V B C$ analysis}

\section{Cell counts}

The numbers of nucleated cells, lymphocytes, monocytes, red blood cells, platelets, and neutrophil granulocytes in 
A

B

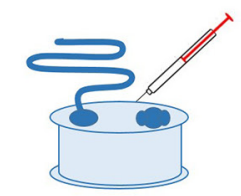

Hemovac blood harvest

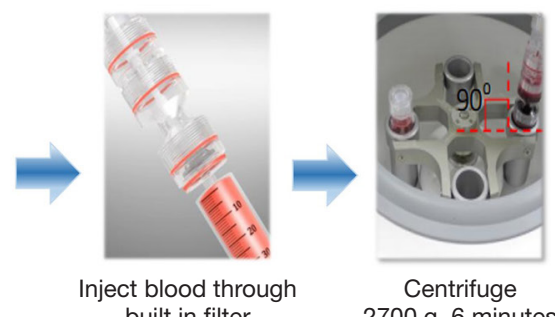
built in filter
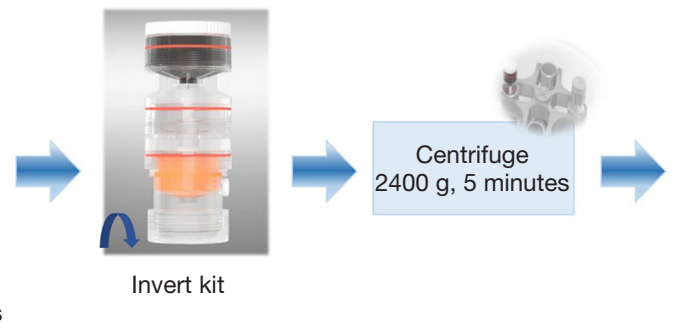

Invert kit

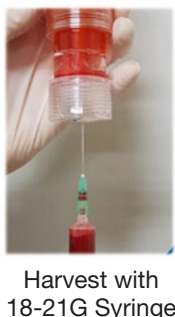

18-21G Syringe

Figure 1 The process of obtaining bone marrow aspirate concentrate (BMAC) and hemovac blood concentrate (HVBC).

the BMA, BMAC, HVB, and HVBC were counted using a cell counter (XE2100, Sysmex, Japan). The number of mononuclear cells (MNCs) was calculated by summing the number of lymphocytes and monocytes.

\section{Isolation of BMA and HVB MNCs}

BMAs were mixed with PBS (Gibco Invitrogen, Grand Island, NY, USA) at a 1:1 ratio. The mixture was loaded onto a histopaque layer $(1.077 \mathrm{~g} / \mathrm{mL}$; Sigma chemical co., St. Louis, MO, USA). MNCs were separated by density gradient centrifugation ( $400 \times \mathrm{g}, 25 \mathrm{~min}$, room temperature), washed thrice with alpha minimum essential medium (aMEM; Gibco Invitrogen, Grand Island, NY, USA), filtered using a 70- $\mu \mathrm{m}$ cell strainer (Becton Dickinson, Falcon, Germany), and resuspended. The cells were incubated at $37{ }^{\circ} \mathrm{C}$ with $5 \% \mathrm{CO}_{2}$ in basic medium ( $\alpha \mathrm{MEM}$ containing 10\% FBS, 100 units/mL penicillin, $100 \mu \mathrm{g} / \mathrm{mL}$ streptomycin). The culture flask was washed with PBS to remove the non-adherent cells and incubated further until adherent cells reached confluence. The confluent cells were trypsinized (0.25\% trypsin EDTA), divided into several culture flasks, and incubated in the basic medium. This subculture was performed for further studies, and the same procedure was repeated for HVB.

\section{Colony forming unit-fibroblast (CFU-F) assay}

A CFU-F assay was performed to quantify nonhematopoietic fibroblastic colonies. The isolated mononucleated cells were cultured in $60-\mathrm{mm}$ cell culture dishes (Becton Dickinson/Falcon, Germany) for
14 days at $37{ }^{\circ} \mathrm{C}$ in a humidified atmosphere and $5 \% \mathrm{CO}_{2}$. aMEM (Gibco, Life Technologies, Karlsruhe, Germany) medium supplemented with 20\% FBS (Gibco), penicillin (100 U/mL; Gibco), and streptomycin (100 $\mu \mathrm{g} / \mathrm{mL}$; Gibco) was used for culturing.

After 14 days, adherent cells were fixed with $4 \%$ paraformaldehyde (Biosesang, Seongnam, Korea) for 5 min, washed with PBS, and stained with $1 \%$ crystal violet. The culture plate was placed on a white paper, and colonies were counted macroscopically. The number of stained cell colonies larger than $2.5 \mathrm{~mm}$ in diameter was counted (14).

\section{Flow cytometry}

Surface marker analysis of HVB, HVBC, BMA, and BMAC was performed using a FACSCalibur flow cytometer (BD Biosciences, Heidelberg, Germany). The harvested cells were fixed in $4 \%$ paraformaldehyde at $4{ }^{\circ} \mathrm{C}$ for $30 \mathrm{~min}$ and washed in flow cytometry buffer (FCB, BD Biosciences, Heidelberg, Germany). Subsequently, the cells were incubated with a blocking buffer for $30 \mathrm{~min}$, followed by centrifugation to remove the blocking buffer. The cells were aliquoted at $1 \times 10^{6}$ for antibody treatment. Cells were stained with PE-labeled antibodies (Abs; CD44, CD29) and APC-labeled Abs (CD90, CD105) (BD Biosciences, San Jose, CA, USA).

\section{Cell proliferation assay}

Cell proliferation was assessed using the cell counting kit (CCK-8) assay (Dojindo, Japan). Briefly, mesenchymal stem cells (MSCs) isolated from the HVBC and BMAC 
were seeded at $1 \times 10^{5}$ cells/well in a 96-well plate. The assay was performed from 1 to 7 days after cell seeding. MSCs from each time point were mixed with $10 \mathrm{uL}$ of CCK- 8 solution/well and incubated for $2 \mathrm{~h}$ at $37{ }^{\circ} \mathrm{C}$. The cellular dehydrogenase activity of the cells was then measured at $450 \mathrm{~nm}$ using a microplate reader. The assay was performed in triplicate.

\section{Transwell migration assay}

Migration assays were performed in Transwell plates (cat no. 3422, Corning Costar, Cambridge, MA, USA), $6.5 \mathrm{~mm}$ in diameter with $8 \mu \mathrm{m}$ pore filters. P2 MSCs $\left(5 \times 10^{5}\right.$ cells $)$ isolated from the HVBC and BMAC were added to the upper chamber in basal medium ( $\alpha$ MEM without FBS). After overnight culture, $20 \%$ FBS $\alpha$ MEM was added to the bottom chamber. Basal medium served as a negative control. After $12 \mathrm{~h}$ incubation at $37^{\circ} \mathrm{C}$, with $5 \% \mathrm{CO}_{2}$, the upper chamber of the filters was carefully washed with cold PBS, and cells remaining on the upper side were removed with a cotton swab. Migrated cells through the chamber, or adhered to the lower membrane, were fix in $4 \%$ paraformaldehyde. After staining with $0.1 \%$ crystal violet, the images were observed microscopically. The absorbance of migrated cells was measured at $520 \mathrm{~nm}$ after being dissolved in $100 \%$ methanol. Each experiment was performed in triplicate.

\section{Multi-lineage differentiation}

MSCs isolated from the HVBC and BMAC were tested for their osteogenic, adipogenic, and chondrogenic differentiation potentials. Briefly, the cells $\left(2 \times 10^{4}\right.$ cells/ well, passage 3 ) were seeded in 6-well plates and treated with the osteogenic and adipogenic induction medium for 2 weeks. Culture media were changed every 3 days. For osteogenic differentiation, cultured cells were washed thrice with DPBS (Gibco Invitrogen, Grand Island, NY, USA) and fixed in $4 \%$ paraformaldehyde at $4{ }^{\circ} \mathrm{C}$ for $10 \mathrm{~min}$. Mineralization of the extracellular matrix as an indicator of osteogenic differentiation was observed using Alizarin red S and alkaline phosphatase (ALP) staining $(15,16)$.

For adipogenic differentiation, cells were washed thrice with DPBS and fixed in $4 \%$ paraformaldehyde at $4{ }^{\circ} \mathrm{C}$ for $20 \mathrm{~min}$. The cells were treated with Oil Red O staining dye to visualize the lipids. For quantitative measurements, Oil Red $\mathrm{O}$ was eluted by dissolving in isopropanol, and the absorbance was measured at $520 \mathrm{~nm}$.

For chondrogenic differentiation, the pelleted culture was used. Here, $2.5 \times 10^{5}$ cells (passage 3 ) were resuspended in the chondrogenic differentiation medium in $15-\mathrm{mL}$ polypropylene tubes. After the cells were centrifuged at $500 \times \mathrm{g}$ for $5 \mathrm{~min}$ to form aggregates, they were incubated at $37^{\circ} \mathrm{C}$ in a humidified atmosphere of $5 \% \mathrm{CO}_{2}$. The aggregates were cultivated for 21 days, and the medium was changed every 3 days. On the $21^{\text {st }}$ day, the cell pellets were fixed in $10 \%$ formalin and embedded in paraffin. Sections of the cell pellets were stained with type II collagen, Alcian blue ( $\mathrm{pH} 2.5$ ), Safranin O, and toluidine blue to identify the collagen content and sulfated proteoglycans in the extracellular matrix. Hematoxylineosin staining was performed for morphological observation of the cells.

\section{Adipogenic differentiation medium}

This medium was comprised of the following: Dulbecco's modified Eagle's medium-high glucose (DMEM-HG; 11965-084, Gibco-Life Technologies, Carlsbad, CA, USA) containing $10^{-6} \mathrm{M}$ dexamethasone, $10 \mu \mathrm{g} / \mathrm{mL}$ insulin, $100 \mu \mathrm{M}$ indomethacin, and $500 \mu \mathrm{M}$ 3-isobutyl-1methylxanthine.

\section{Osteogenic differentiation medium}

This medium was comprised of the following: $\alpha M E M$ (12571-063, Gibco-Life Technologies, Carlsbad, CA, USA) containing $50 \mu \mathrm{g} / \mathrm{mL} \mathrm{L-ascorbic} \mathrm{acid,} 10 \mathrm{mM}$ b-glycerophosphate, and $10 \mathrm{nM}$ dexamethasone.

\section{Chondrogenic differentiation medium}

This medium was comprised of the following: DMEMHG (11965-084, Gibco-Life Technologies, Carlsbad, CA, USA) containing $10^{-7} \mathrm{M}$ dexamethasone, $10 \mathrm{ng} / \mathrm{mL}$ transforming growth factor beta 3 (TGF- $\beta 3$ ), $100 \mu \mathrm{g} / \mathrm{mL}$ sodium pyruvate, $40 \mu \mathrm{g} / \mathrm{mL}$ proline, $25 \mu \mathrm{M}$ ascorbic acid-2-phosphate, $100 \mathrm{U} / \mathrm{mL}$ penicillin, $100 \mu \mathrm{g} / \mathrm{mL}$ streptomycin, and $1 \%(\mathrm{v} / \mathrm{v})$ ITS plus $(5 \mu \mathrm{g} / \mathrm{mL}$ insulin, $5 \mu \mathrm{g} / \mathrm{mL}$ transferrin, $5 \mu \mathrm{g} / \mathrm{mL}$ selenous acid). All reagents were purchased from Sigma-Aldrich (St Louis, MO, USA).

\section{Quantitative real-time polymerase chain reaction (qRT- PCR)}

Total RNA from the MSCs of HVBC and BMAC showing osteogenic, adipogenic, and chondrogenic differentiation was extracted using the RNeasy mini kit (74104, Qiagen, Hilden, Germany). The RNA samples were reverse transcribed into cDNA using the QuantiTect reverse transcription kit (205311, Qiagen, Hilden, Germany) 
Table 1 List of primers used in qRT-PCR for multi-differentiation genes

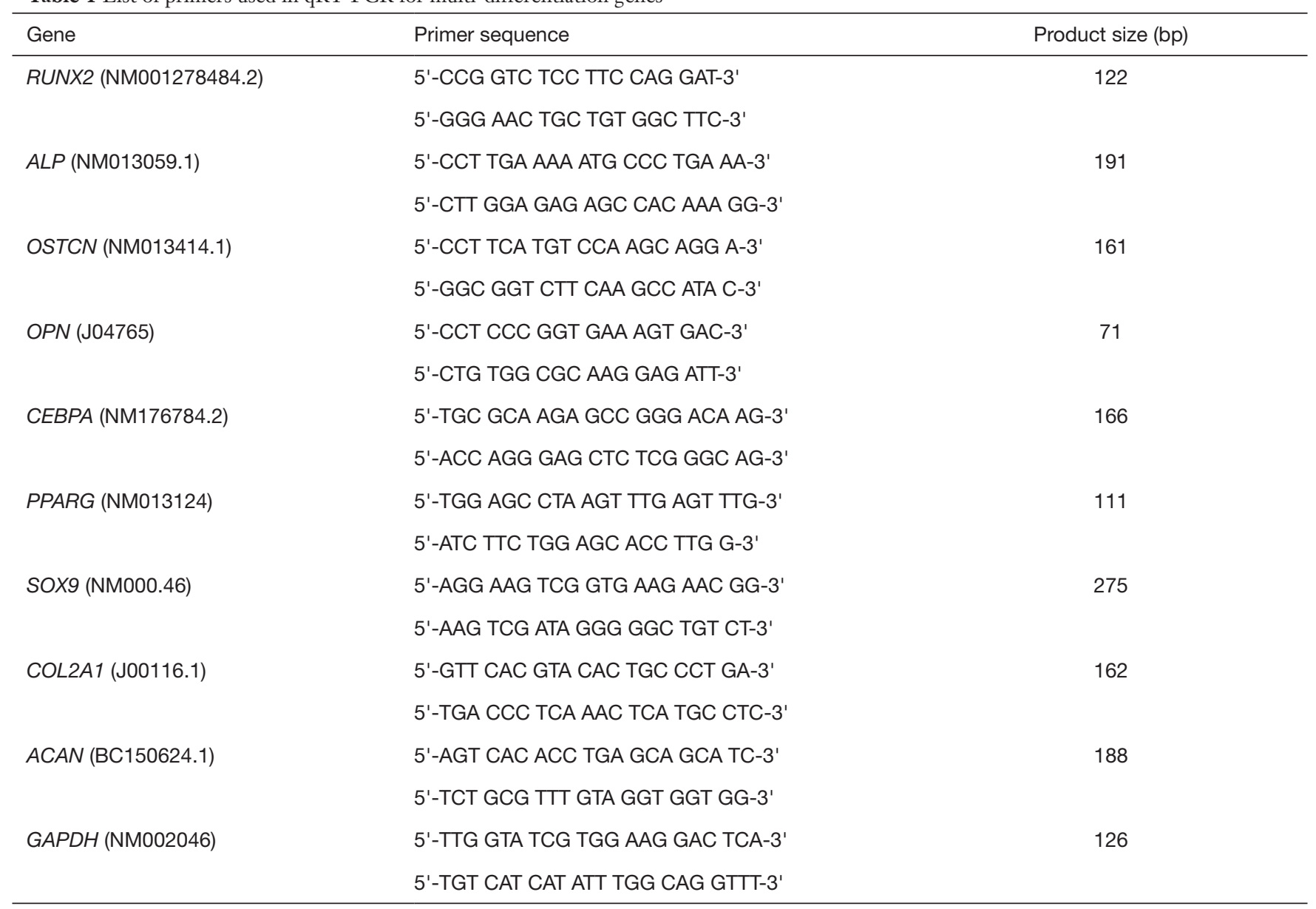

ALP, alkaline phosphatase; C/EBP $\alpha$, CCAAT enhancer binding protein alpha; PPAR $\gamma$, peroxisome proliferator-activated receptor gamma; RUNX2, runt-related transcription factor; SOX9, SRY-BOX transcription factor 9.

following the manufacturer's instruction. All samples were analyzed using SYBR green (A6001, Promega, Madison, WI, USA) on a Promega qPCR system, and the relative expression levels were determined according to the $2^{-\Delta \Delta C t}$ method. Primer sequences used for the qRT-PCR analysis is provided in Table 1 .

\section{Statistical analysis}

Statistical analysis was performed using SAS software version 9.2 (SAS Institute Inc., Cary, NC, USA). All variables were summarized using standard descriptive statistics such as mean, $\mathrm{SD}$, median, and range. The Mann-Whitney test was used for comparative analyses between groups. Statistical significance is described as $\mathrm{P}<0.05$.

\section{Results}

\section{Automatic cell counts}

Automatic cell counting was performed to compare the number of cells before and after concentrating BMA and HVB. The cells were increased in BMAC and HVBC (Table 2).

\section{Colony forming unit-fibroblast assay}

CFU-F assay results demonstrate the self-renewal capacity of cells able to form new fibroblast colonies from single cells. The density and size of the colonies were found to be different according to the proliferative status of cells. A higher density and larger size of colonies indicates the higher proliferative potential of cells (14). Small fibroblastic 
Table 2 Cell number comparison of hemovac and bone marrow samples

\begin{tabular}{lccccccc}
\hline Sample & $\begin{array}{c}\text { Number of } \\
\text { samples (cases) }\end{array}$ & $\begin{array}{c}\text { Sample } \\
\text { description }\end{array}$ & $\begin{array}{c}\text { Volume } \\
(\mathrm{mL})\end{array}$ & WBC $\left(\times 10^{3} / \mu \mathrm{L}\right)$ & $\mathrm{LYMPH}\left(\times 10^{3} / \mu \mathrm{L}\right)$ & $\mathrm{MONO}\left(\times 10^{3} / \mu \mathrm{L}\right)$ & $\mathrm{PLT}\left(\times 10^{3} / \mu \mathrm{L}\right)$ \\
\hline Hemovac & 20 & HVB & 40 & $7.89 \pm 2.84$ & $1.0 \pm 0.51$ & $0.15 \pm 0.08$ & $31.0 \pm 13.8$ \\
& & HVBC & 4 & $28.36 \pm 19.11$ & $4.87 \pm 3.67$ & $0.8 \pm 0.74$ & $125.35 \pm 97.78$ \\
Bone marrow & 15 & BMA & 40 & $13.6 \pm 5.96$ & $4.29 \pm 1.45$ & $1.63 \pm 1.34$ & $104.8 \pm 65.26$ \\
& & BMAC & 4 & $97.62 \pm 55.64$ & $24.38 \pm 15.38$ & $7.56 \pm 5.54$ & $560.0 \pm 339.56$ \\
\hline
\end{tabular}

BMA, bone marrow aspirate; BMAC, bone marrow aspirate concentrate; HVB, hemovac blood; HVBC, hemovac blood concentrate; LYMPH, lymphocyte; MONO, monocyte; PLT, platelet; WBC, white blood cell.

colonies were observed on culture plates isolated from HVB and BMA at 5-7 days of culture. After 14 days, colonies were analyzed using a light microscope with crystal violet staining. The number of colonies that were $>2.5 \mathrm{~mm}$ in size was counted (Figure $2 A$ ). The number of colonies were $2.30 \pm 1.87$ (20 patients) in HVB, and $3.13 \pm 1.73$ (15 patients) in BMA, with no statistically significant difference $(\mathrm{P}=0.365)$. Meanwhile, there were $14.30 \pm 9.45$ (20 patients) colonies in $\mathrm{HVBC}$, and 17.07 \pm .89 (15 patients) in BMAC, without statistically significant differences observed $(\mathrm{P}=0.187)$. However, the number of colonies obtained before and after concentration were significantly different in each group $(\mathrm{P}<0.05$; Figure $2 B)$.

\section{Flow cytometry}

Surface expression markers in HVB, HVBC, BMA, and BMAC were confirmed by flow cytometry. CD29, CD44, CD90, and CD105, which are MSC-specific markers, were evaluated. All were highly expressed $(>96 \%)$ in HVB, HVBC, BMA, and BMAC (Figure 3). However, CD34 (0.18\% in HVB and $0.39 \%$ in HVBC, $0.08 \%$ in BMA and $2.82 \%$ in BMAC), CD45 (0.41\% in HVB and $0.49 \%$ in HVBC, $0.28 \%$ in BMA and $3.08 \%$ in BMAC), and HLADR $(0.21 \%$ in HVB and $0.12 \%$ in HVB, $0.98 \%$ in BMA and $0.18 \%$ in BMAC) showed negative expression (<4\%). Figure 3 shows a summary of the surface marker expression analysis of HVB, HVBC, BMA, and BMAC, which was associated with no significant variation.

\section{Isolated cells from $H V B$ and $B M A$}

Cells isolated from HVB and BMA were cultured and observed 3-5 days after the initial plating Figure $4 A$ (a, c), and maintained in $\alpha M E M$ supplemented with $10 \%$ FBS and penicillin. These cells readily expanded in vitro, attached to the well, and showed a fibroblast-like morphology. The viability of the cells in each passage was greater than $98 \%$, with no morphological changes observed Figure $4 A$ (b, d).

\section{Cell proliferation}

The proliferation of MSCs isolated from the HVBC and BMAC was observed. After day 1 to 7 of culturing, the optical density (OD) of cells increased from $0.087 \pm 0.012$ to $0.508 \pm 0.028$ in $\mathrm{HVBC}$, and $0.083 \pm 0.010$ to $0.552 \pm 0.003$ in BMAC (average $\pm \mathrm{SD}$; Figure $4 B$ ). There was no significant difference between the HVBC and BMAC in $\mathrm{OD}$ value from days 1 to 3 (Figure $4 B, \mathrm{P}<0.05$ ). Meanwhile, the $\mathrm{OD}$ values representing proliferation during days 4 to 7 were significantly different between the HVBC and BMAC (Figure $4 B, \mathrm{P}<0.05, \mathrm{P}<0.01$ ). The $\mathrm{OD}$ values were $0.383 \pm 0.022$ on day $4,0.502 \pm 0.011$ on day $5,0.519 \pm 0.009$ on day 6 in HVBC, and $0.451 \pm 0.016$ on day $4,0.540 \pm 0.016$ on day 5 , and $0.553 \pm 0.004$ on day 6 in BMAC. The pattern of increasing OD values for cell numbers between the $\mathrm{HVBC}$ and BMAC was similar.

\section{Cell migration}

Next, the migration ability of MSCs isolated from the HVBC and BMAC was observed using crystal violet staining. The cells from the HVBC and BMAC were morphologically similar (Figure 4C). The measurement of the OD value of stained cells represents the number of migrated cells. The OD value of $20 \%$ FBS $\alpha$ MEM was $1.182 \pm 0.024$, which was approximately 2.2 -fold higher than the control ( $\alpha$ MEM without FBS; $0.538 \pm 0.045)$ in HVBC. Meanwhile, the OD value of $20 \%$ FBS $\alpha$ MEM was $1.18 \pm 0.019$, and approximately 2.3 -fold higher than the control ( $\alpha M E M$ without FBS; $0.515 \pm 0.019$ ) in BMAC. There was no significant difference between the HVBC and 

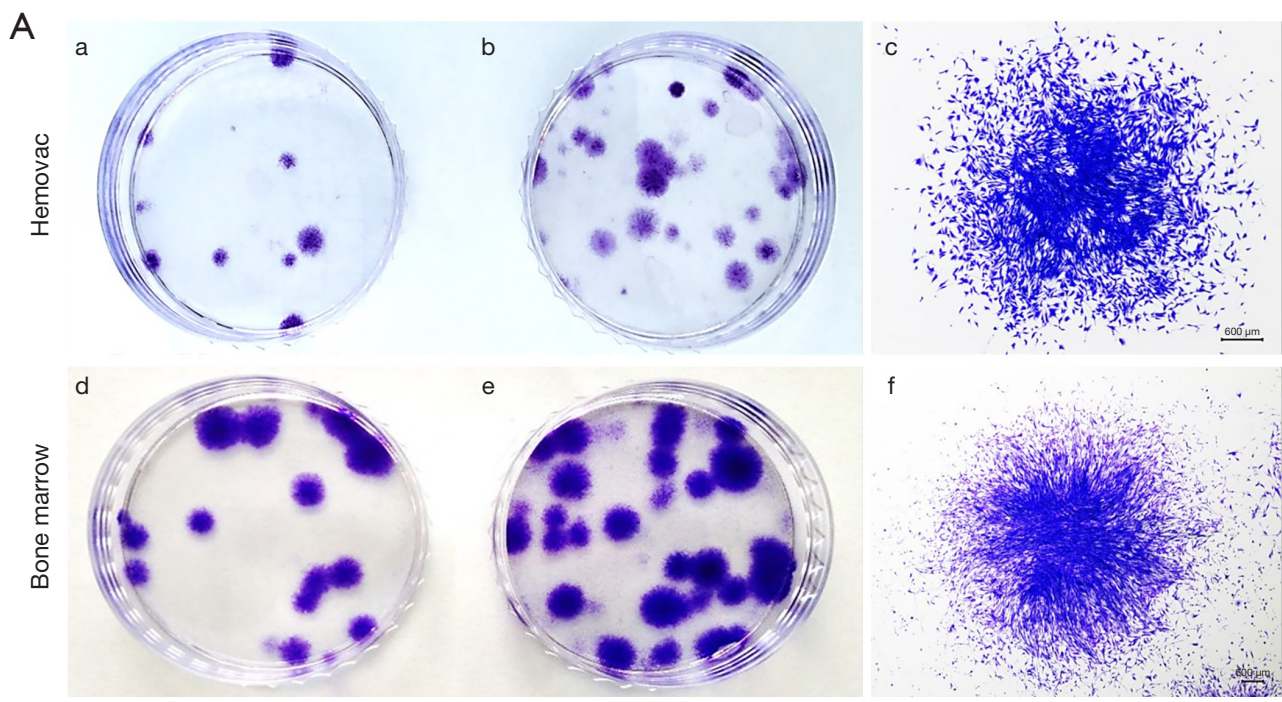

B

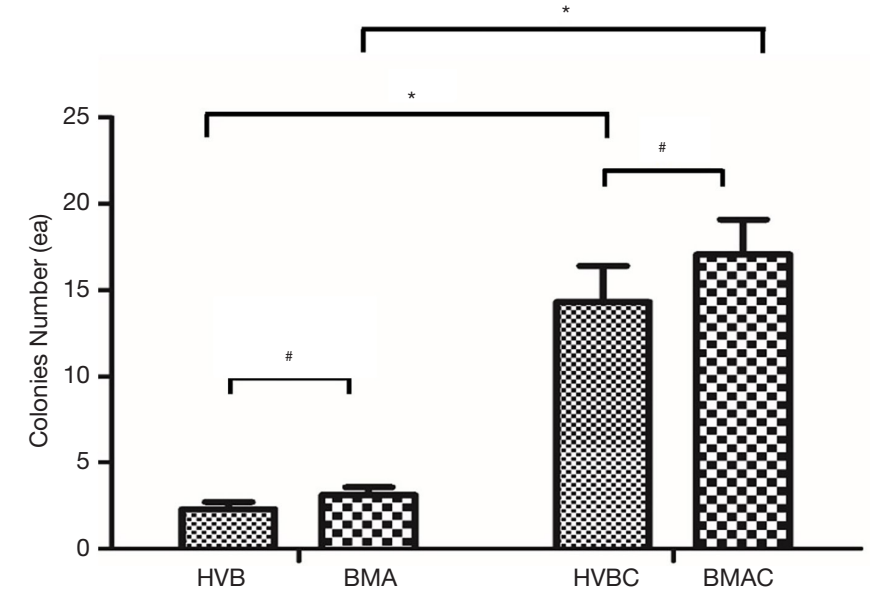

Figure 2 Colony forming unit-fibroblast (CFU-F) assay. (A) Colonies (P0) stained with 1\% crystal violet on the 14th day after plating. (a) HVB (hemovac blood), (b) HVBC (hemovac blood concentrate), (c) bone marrow (d) BMA (bone marrow aspirate), (e) BMAC (bone marrow aspirate concentrate), (f) is a representative colony image. Scale bar $=600 \mu \mathrm{m}$. (B) After 14 days of culture, colonies were counted. The number of colonies in HVB and BMA was not significantly different $(\mathrm{P}=0.365)$. The number of colonies in $\mathrm{HVBC}$ and $\mathrm{BMAC}$ was not significantly different $(\mathrm{P}=0.187)$. Hemovac $\mathrm{n}=20$, bone marrow $\mathrm{n}=15$; $^{\text {, }} \mathrm{P}>0.05$. However, the number of colonies in $\mathrm{HVB}$, $\mathrm{BMA}$ (before concentrate) and HVBC, BMAC (after concentrate) in each group showed a significant difference. *, $\mathrm{P}<0.05$.

BMAC in OD values (Figure $4 D, \mathrm{P}<0.05$ ).

\section{Multi-lineage differentiation (chondrogenic, osteogenic, and adipogenic)}

Adipogenic differentiation was confirmed by Oil Red $\mathrm{O}$ staining to identify intracellular lipids. Intracellular lipid droplets in isolated cells from HVB and BMA were observed. Lipid droplets were not found in the undifferentiated condition (Figure $5 A$ ). Absorbance values were $0.311 \pm 0.011 \mathrm{~nm}$ for $\mathrm{HVBC}$, and $0.371 \pm 0.051 \mathrm{~nm}$ for BMAC in the undifferentiated condition, and $0.945 \pm$ $0.051 \mathrm{~nm}$ for $\mathrm{HVBC}$, and $0.860 \pm 0.051 \mathrm{~nm}$ for BMAC in the differentiated condition (Figure 5B). Absorbance values in the undifferentiated and differentiated conditions between HVBC and BMAC were not significantly different $(\mathrm{P}>0.05)$. 
A HVB
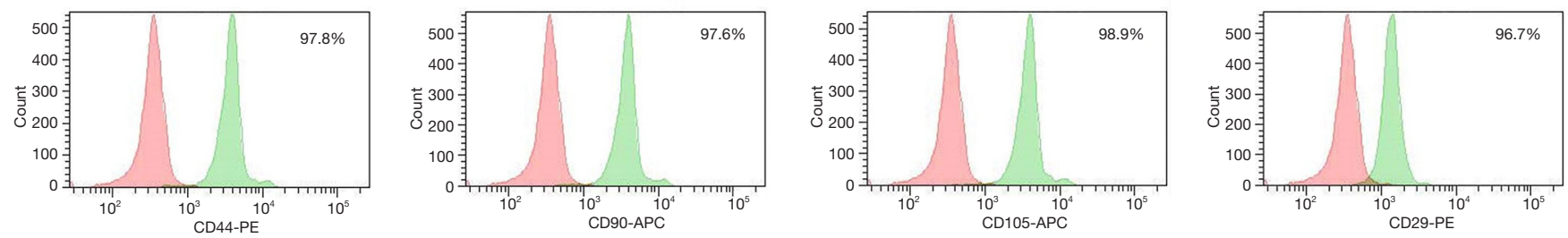

B HVBC
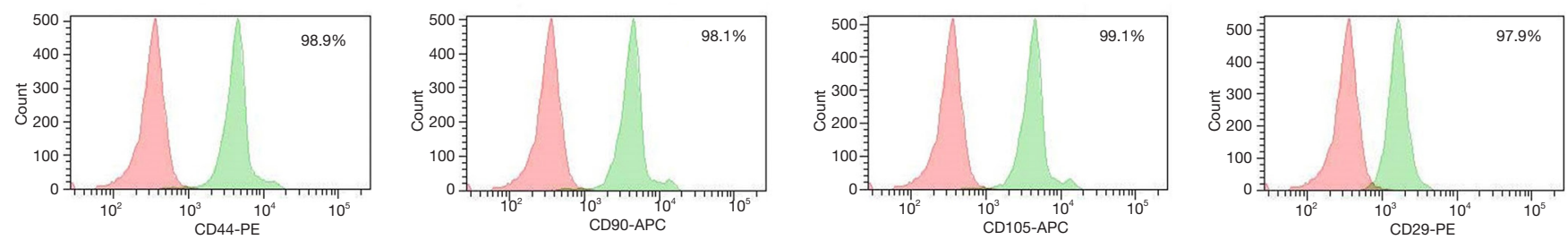

C BMA
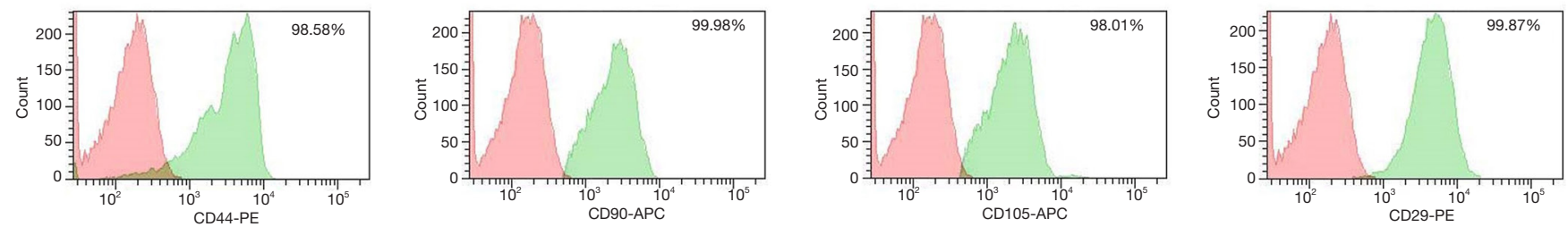

D BMAC
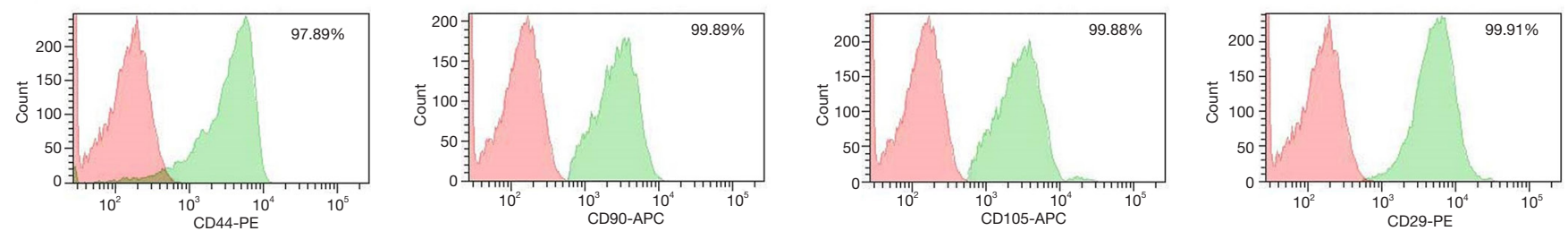

Figure 3 Surface marker expression of mesenchymal stem cells (MSCs) derived from HVB, HVBC, BMA, and BMAC. (A) HVB, (B) HVBC, (C) BMA, and (D) BMAC. MSCs were positive for CD44, CD90, CD 105, and CD29 (>96\%). HVB, hemovac blood; HVBC, hemovac blood concentrate; BMA, bone marrow aspirate; BMAC, bone marrow aspirate concentrate.

However, absorbance between the undifferentiated and differentiated conditions for HVBC and BMAC were significant $(\mathrm{P}<0.05$; Figure 5B).

Osteogenic differentiation was identified by Alizarin red $S$ (calcification of the extracellular matrix) and ALP staining (Figure 6). Calcification during osteogenic differentiation appears as large crystal clusters among cells. Crystal clusters (calcification in the extracellular matrix) were stained red with Alizarin red S staining (Figure 6A). Absorbance values were $0.044 \pm 0.001 \mathrm{~nm}$ for HVBC and $0.042 \pm 0.001 \mathrm{~nm}$ for BMAC in the undifferentiated condition and $0.419_{ \pm}$ $0.012 \mathrm{~nm}$ for HVBC and $0.516 \pm 0.013 \mathrm{~nm}$ for BMAC in the differentiated condition. Absorbance values between HVBC and BMAC in the differentiated condition were significantly different after Alizarin red staining $(\mathrm{P}<0.001)$ with a higher value in BMAC (Figure $6 B$ ). The absorbance value of the undifferentiated and differentiated conditions between HVBC and BMAC in the ALP assay did not show any significant difference with values of $47.025 \pm 0.837 \mathrm{U} / \mathrm{mL}$ in $\mathrm{HVBC}$, and $48.548 \pm 3.195 \mathrm{U} / \mathrm{mL}$ in BMAC $(\mathrm{P}>0.05$; Figure 6B).

To evaluate chondrogenic differentiation, hematoxylineosin staining was performed to observe the morphology of cells, and Alcian blue $\mathrm{pH}$ (2.5) and toluidine blue staining 


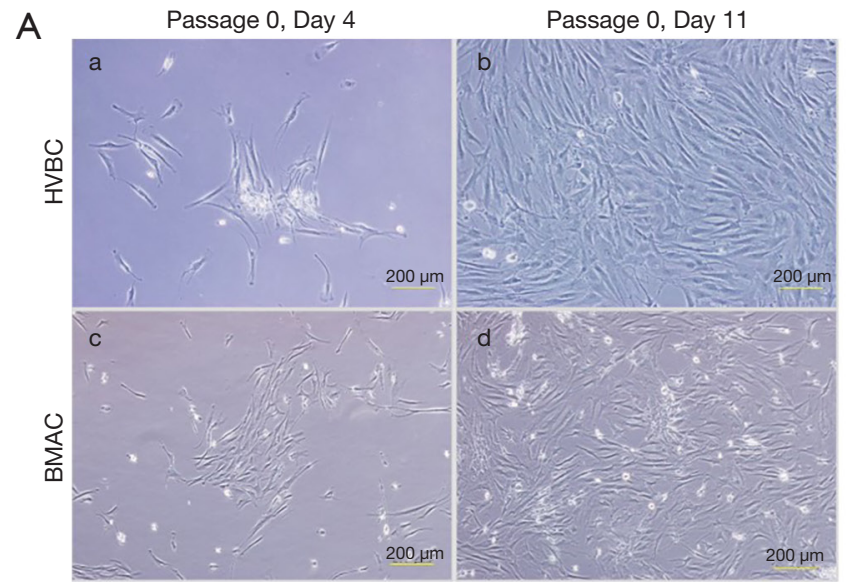

B

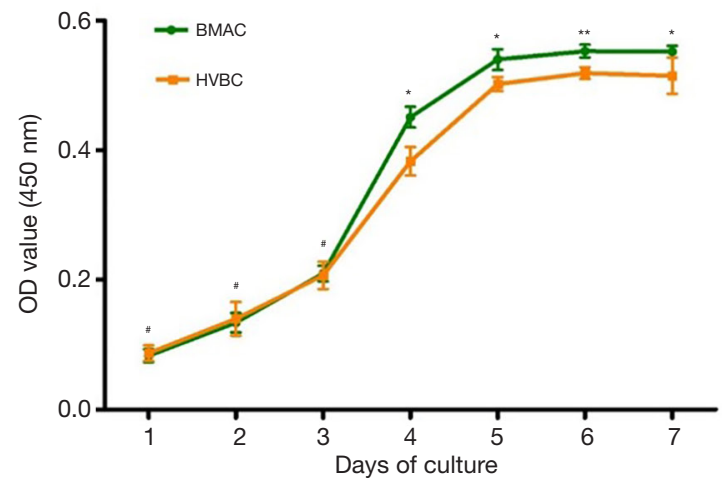

C
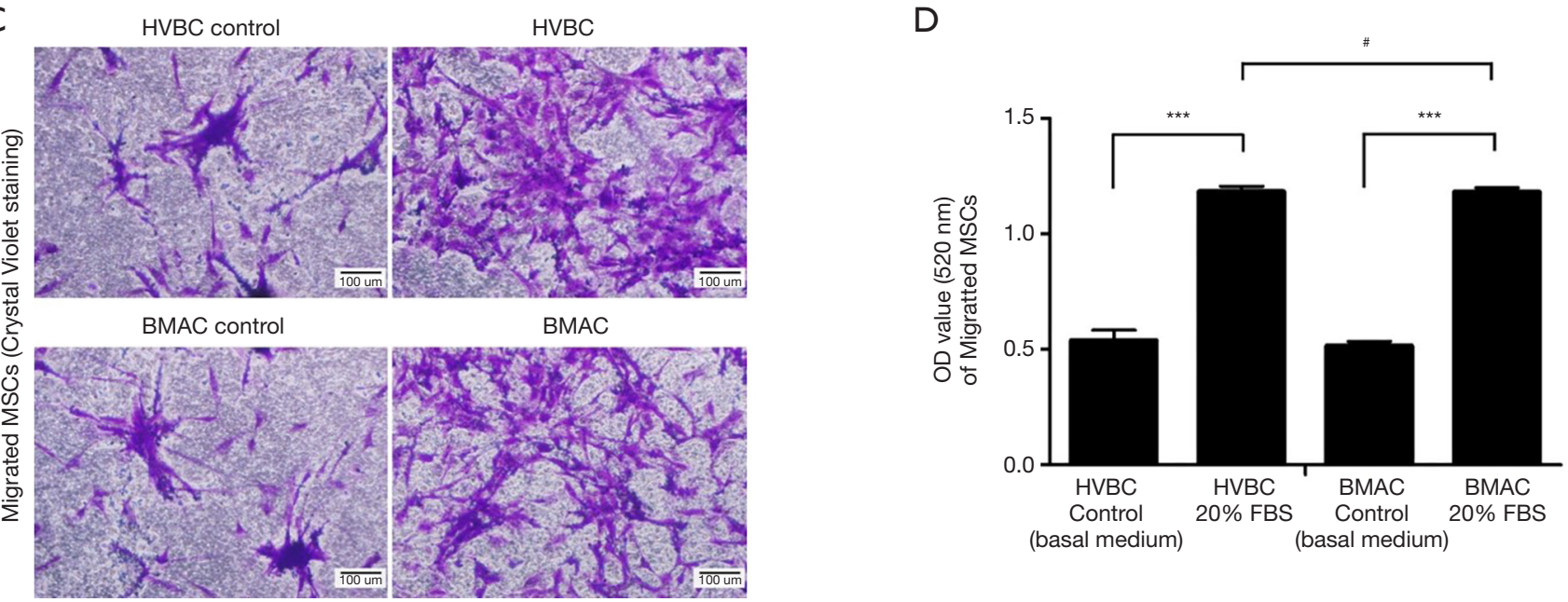

Figure 4 Cell morphology, proliferation and migration ability. (A) Morphology of adherent cells. Cells were isolated from hemovac blood (HVB; a and b) and bone marrow aspirate (BMA; c and d). A (a and c) at 4 days, small fibroblastic mesenchymal stem cells (MSCs) were observed that were loosely arranged. A (b and d) at 11 days after initial plating, cells were confluent. Scale bar $=200 \mu \mathrm{m}$. (B) Proliferation of cells from BMAC and HVBC incubated for 1 to 7 days and analyzed by CCK-8 assay. The proliferation rate of BMAC was higher than that of HVBC from days 4 to 7 (", $\left.\mathrm{P}>0.05,{ }^{*}, \mathrm{P}<0.05,{ }^{* *}, \mathrm{P}<0.01\right)$. (C) Representative images of migrated cells for the HVBC control, HVBC, BMAC control, and BMAC. (D) Quantitative analyses of migrated cells in BMAC and HVBC (***, $\mathrm{P}<0.001$, ,, $\mathrm{P}<0.05$ ).

was performed to observe the pericellular proteoglycan and type II collagen deposition (Figure 7). Many round cells with surrounding lacuna were observed after hematoxylineosin staining (black arrow, Figure $7 B, D$ ). The rich extracellular matrix surrounding the cells was observed in the chondrogenic differentiation group of both HVBC and BMAC (Figure $7 B, D$ ). The pellets in the differentiated condition showed strong toluidine blue (Figure $7 N, P$ ) and Alcian blue $\mathrm{pH}$ (2.5) staining (indicative of cartilage matrix;
\# Figure 7f,L). Safranin O staining and the morphology of the cells suggested that a cartilaginous matrix had been synthesized. The highly stained area after toluidine blue and Alcian blue $\mathrm{pH}$ (2.5) staining corresponded to the safranin $\mathrm{O}$-stained areas in the chondrogenic differentiation condition (Figure 7F,H). Type II collagen expression inn $\mathrm{HVBC}$ and BMAC was confirmed via immunohistochemical staining (Figure $7 R, T$ ). Type II collagen is the main collagen component of the extracellular matrix and comprises the 


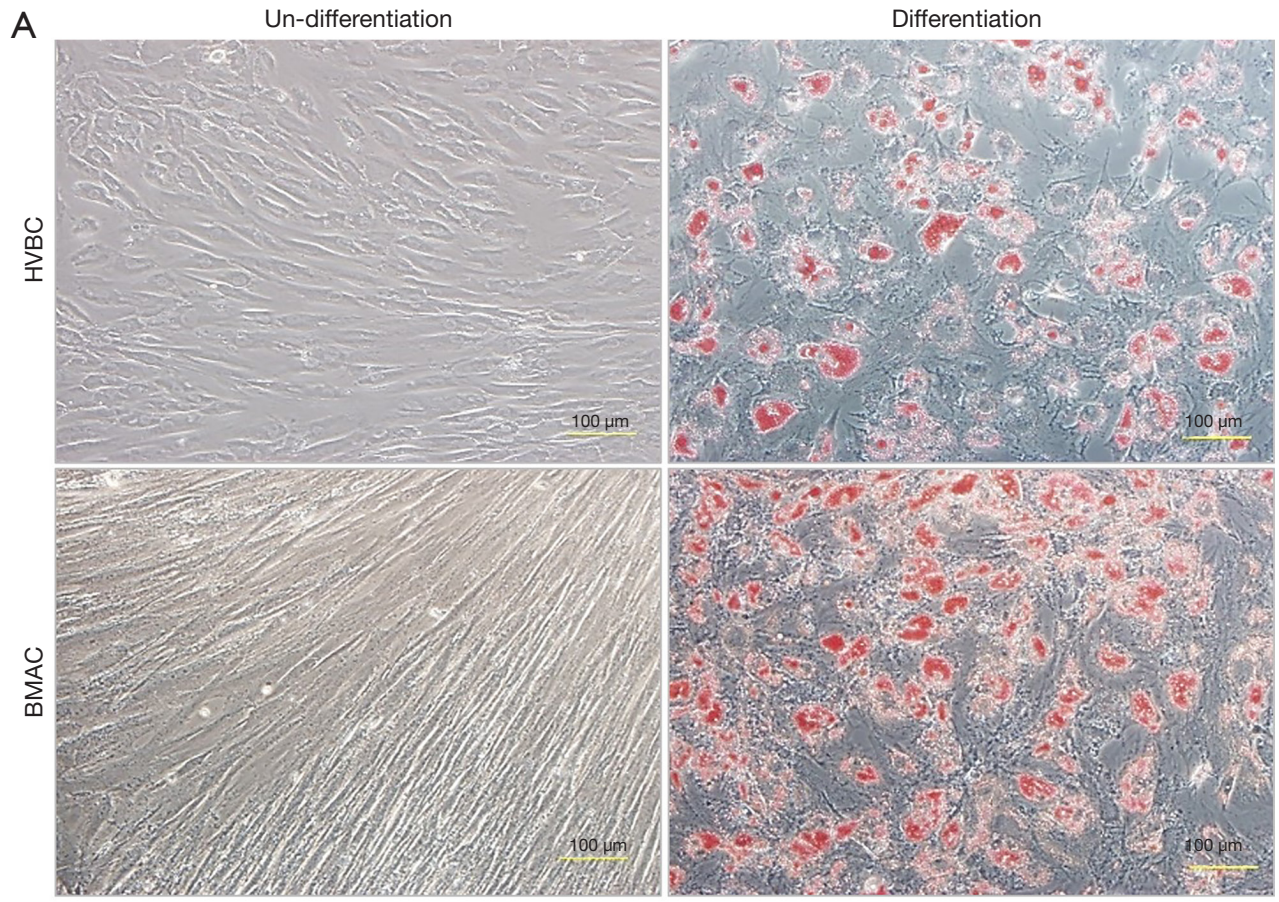

B

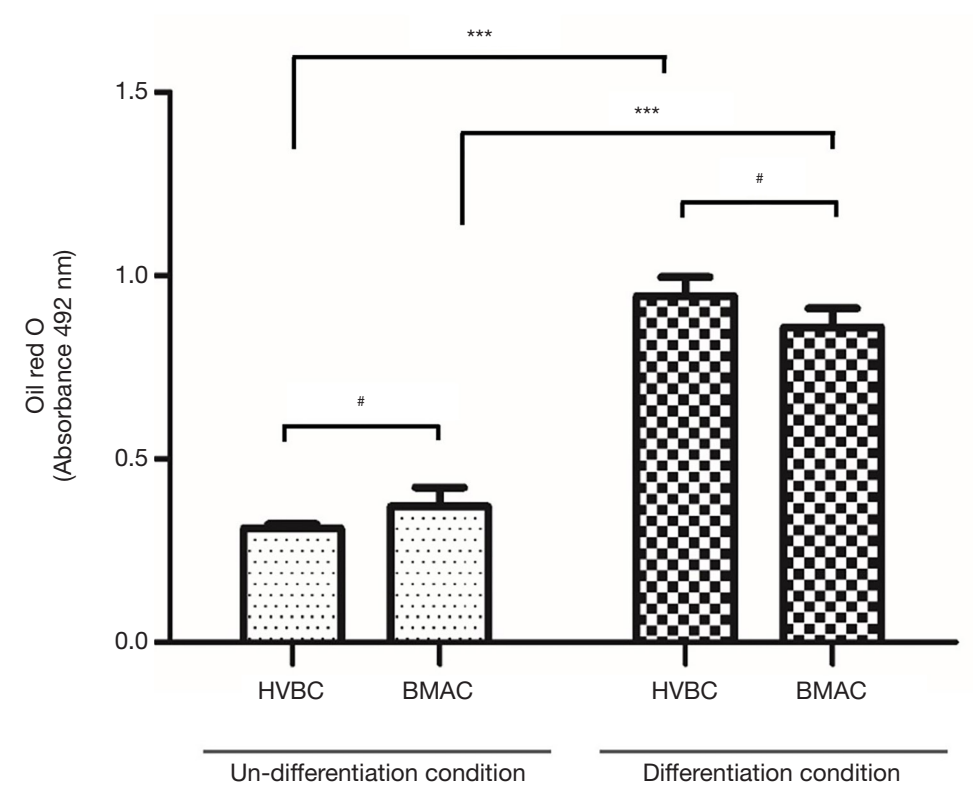

Figure 5 Adipogenic differentiation of mesenchymal stem cells (MSCs) derived from HVBC and BMAC on the 14th day of culture. (A) The accumulation of intracellular lipid drops was observed by Oil Red O staining, indicating adipogenic differentiation. Scale bar $=100 \mu \mathrm{m}$. (B) Absorbance results of HVBC (average $0.945 \pm 0.051 \mathrm{~nm}$ ) and BMAC (average $0.86 \pm 0.051 \mathrm{~nm}$ ) in the differentiation condition were not significantly different $(\mathrm{P}=0.108) . \mathrm{n}=3,{ }^{*}, \mathrm{P}>0.05,{ }^{* * *}, \mathrm{P}<0.001$. HVBC, hemovac blood concentrate; BMAC, bone marrow aspirate concentrate. 
A
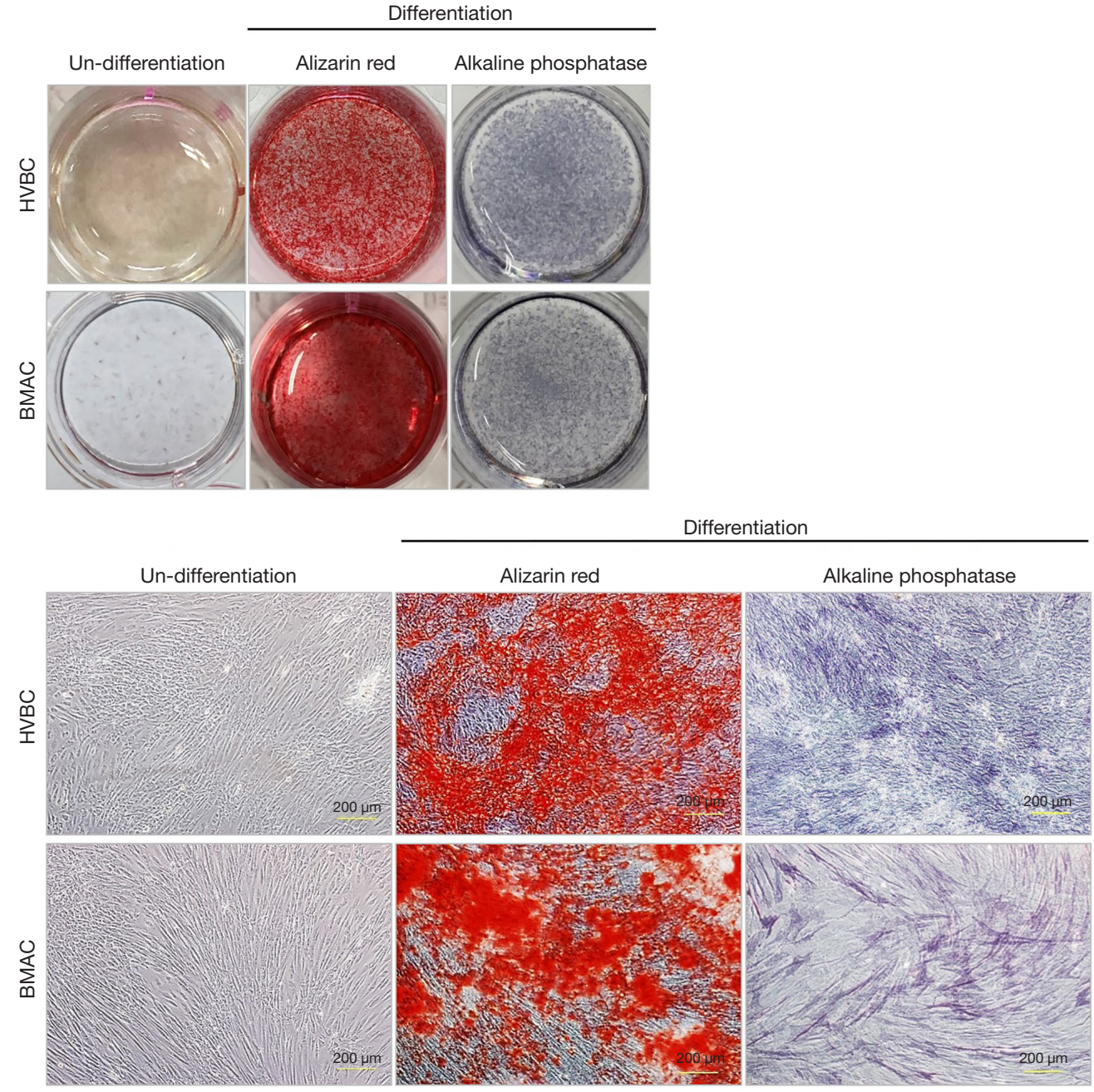

B

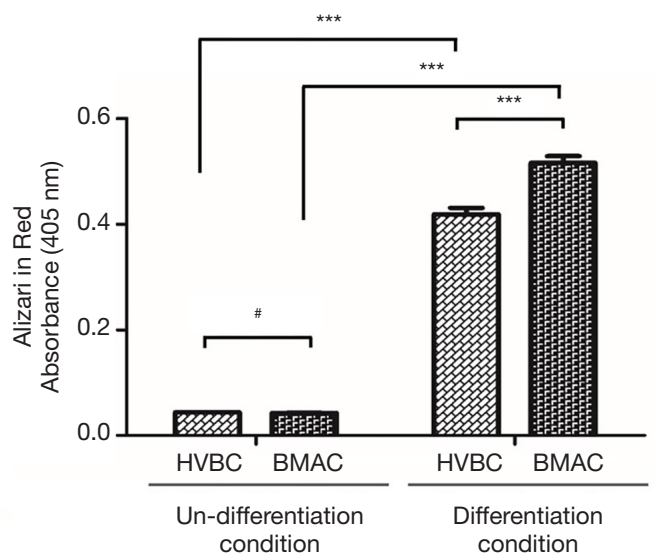

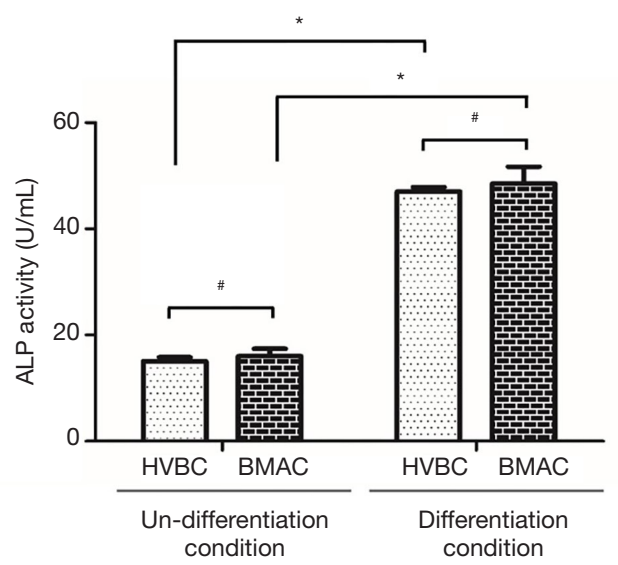

Figure 6 Osteogenic differentiation of mesenchymal stem cells (MSCs) derived from HVBC and BMAC on the 14th day of culture. (A) Alizarin red S was used to observe calcium deposition. The blue color represents alkaline phosphatase. Scale bar $=200 \mu \mathrm{m}$. (B) Absorbance results of Alizarin red S increased after differentiation as compared to that before differentiation. Alkaline phosphatase activity increased after differentiation as compared to that before differentiation, and the results were significantly different (Alizarin red $\mathrm{S}$; *** $\mathrm{P}<0.001$, alkaline phosphatase: *, $\mathrm{P}<0.05)$. HVBC, hemovac blood concentrate; BMA, bone marrow aspirate; BMAC, bone marrow aspirate concentrate. 

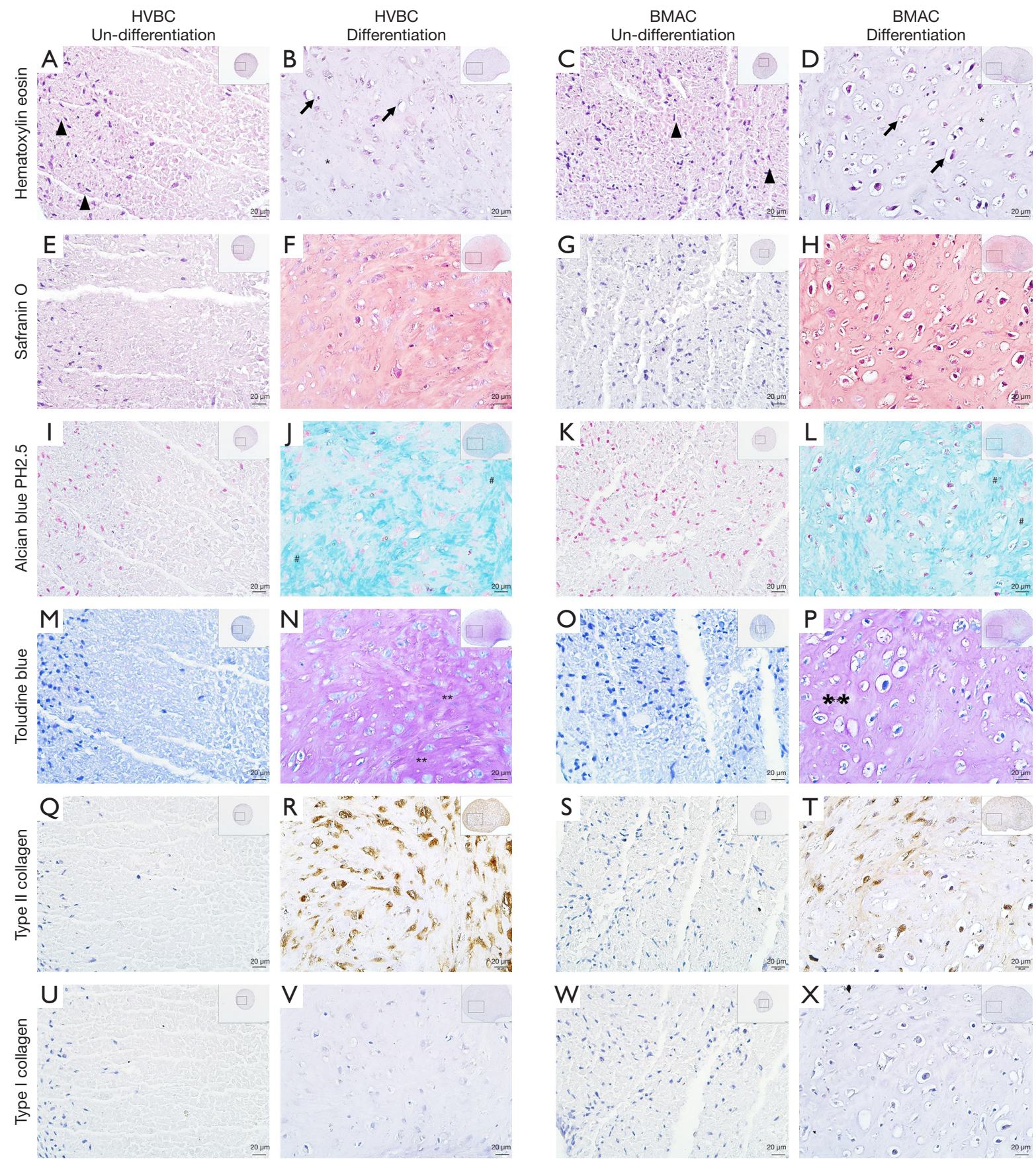

Figure 7 Chondrogenic differentiation of mesenchymal stem cells (MSCs) derived from HVBC and BMAC on the 21st day of culture. MSCs were cultured in the form of a pellet $\left(2.5 \times 10^{5}\right.$ cells per pellet). Hematoxylin-eosin (H\&E) staining of the pellets (A-D); Safranin O (E-H); Alcian blue (pH 2.5) (I-L); Toluidine blue (M-P); immunohistochemical staining for detection of type II collagen Q-T) and type I collagen $(\mathrm{U}-\mathrm{X})$. elongated cells were seen in the non-differentiation group (black arrowhead, A,C) and chondrocyte-like cells with lacuna were observed in the chondrogenic differentiation group (black arrow, B,D). Strong staining of safranin O (F,H), Alcian blue (pH 2.5) (blue stain \# of J,L), toluidine blue (purple stain ** of N,P) and type II collagen (R,T) demonstrated the formation of hyaline cartilage-like tissue in the pellets of the chondrogenic differentiation group. Scale bar $=100 \mu \mathrm{m}$. HVBC, hemovac blood concentrate; BMA, bone marrow aspirate; BMAC, bone marrow aspirate concentrate. 
A

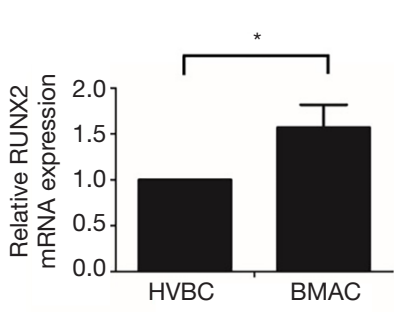

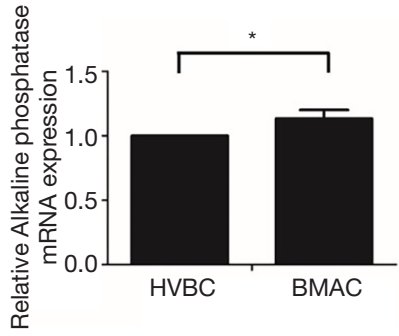
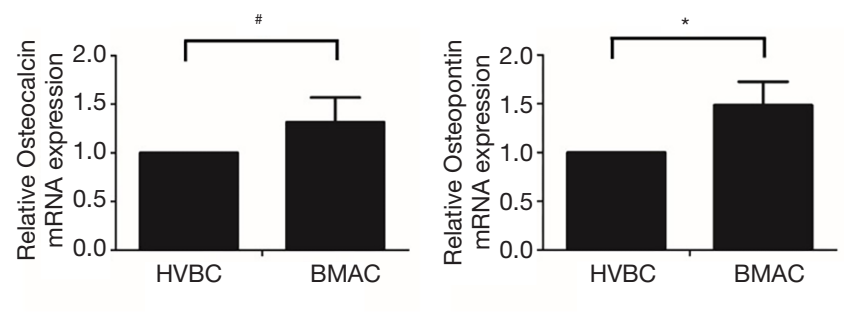

B
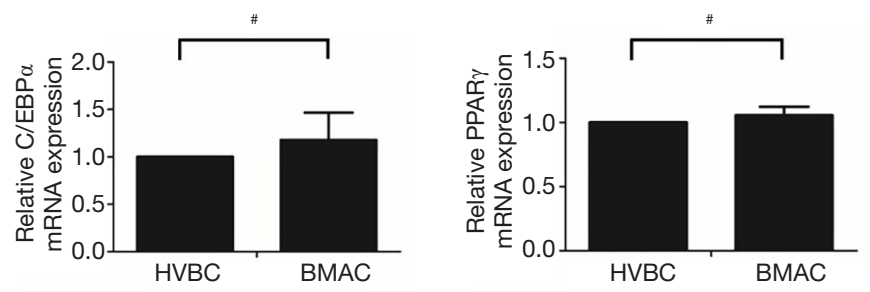

C
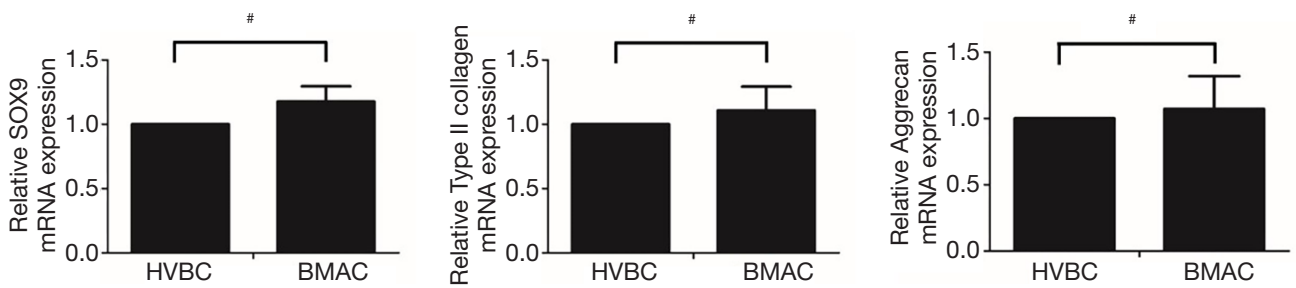

Figure 8 Comparison of multi-differentiation gene expression level between HVBC and BMAC. (A) Expression of osteogenic differentiation genes (RUNX2, osteocalcin, osteopontin and alkaline phosphatase) at 14 days of osteogenic differentiation culture. RUNX2, osteopontin, and alkaline phosphatase gene expression in BMAC was higher than that of HVBC $\left({ }^{*}, \mathrm{P}<0.05\right)$. Osteocalcin expression was not significantly different between the groups. (B) Expression of adipogenic differentiation marker genes (C/EBP $\alpha$ and PPAR $\gamma$ ). No statistically significant difference was observed between HVBC and BMAC. (C) Chondrogenic differentiation marker gene expression (SOX9, aggrecan, type II collagen). No statistically significant difference was observed between HVBC and BMAC (", P>0.05). HVBC, hemovac blood concentrate; BMA, bone marrow aspirate; BMAC, bone marrow aspirate concentrate.

cartilage-specific matrix $(17,18)$. Type I collagen was not detected in any of the groups (Figure $7 V, X$ ).

\section{Gene expression}

Total RNA was extracted from MSCs in HVBC and BMAC on the $14^{\text {th }}$ day of culture after osteogenic and adipogenic differentiation, and on the $21^{\text {st }}$ day of chondrogenic differentiation. Expression of the genes for runt-related transcription factor 2 (RUNX2), osteopontin $(O P N)$, osteocalcin $(O S T C N)$, and $A L P$, were analyzed as osteogenic differentiation markers. RUNX2, OPN and ALP expression levels were higher in BMAC than in HVBC. However, OSTCN expression levels in HVBC and BMAC were not significantly different (Figure $8 A ; \mathrm{P}<0.05, \mathrm{P}>0.05$ ). Further, the adipogenic differentiation markers $P P A R G$ and $C E B P A$ were observed. The expression of PPARG and CEBPA genes after adipogenic differentiation was upregulated; however, the difference between HVBC and BMAC was not significant (Figure $8 B, \mathrm{P}>0.05$ ). Additionally, the genes for type II collagen (COLA1), aggrecan $(A C A N)$, and SOX9 were investigated as chondrogenic differentiationspecific markers (Figure 8C). The expression of all three was significantly upregulated in the chondrogenic differentiation group; however, the difference between $\mathrm{HVBC}$ and BMAC was not statistically significant (Figure $8 C, \mathrm{P}>0.05$ ).

\section{Discussion}

Since stem cell research is an actively progressing field, 
finding an adequate cell source is critical. Bone (19), bone marrow (20), synovium $(21,22)$, adipose tissue (23), cord blood (24), are well known sources (25-27). Additionally, the nasal septum, muscle, and cartilage serve as stem cell sources for musculoskeletal regeneration (28-31).

Bone marrow mesenchymal stem cells (BMSCs) have served as the primary source of stem cells for many years. However, harvesting BMSCs is a painful procedure and they exhibit signs of senescence at an early stage of expansion compared with MSCs derived from other sources $(32,33)$. Nevertheless, BMSCs require a relatively short culture period $(34,35)$, and many clinical studies using this source are actively being conducted. Alternatively, adipose tissue derived MSCs can be readily isolated (35) with morphological and phenotypical characteristics similar to BMSCs, which are stable during the culture period (36). Moreover, although umbilical cord blood derived MSCs (UCB-MSCs) have an associated long cultivation period, they exhibit high proliferation capacity $(37,38)$. Meanwhile, peripheral blood derived MSCs are easily obtained, which is the reason for their application in many animal studies (38-45), however, they are present at low levels in mononuclear cells (38).

Compared to the other sources of stem cells, HVB can be readily obtained after various bone surgeries, including TKA, without the need for special procedures that can cause additional pain and be met with ethical issues. Although the amount of HVB may vary between patients, a sufficient number of MSCs can be obtained through concentration and cultivation of the cells. Nevertheless, the hemovac must be treated carefully and aseptically following TKA. Should the HVB become contaminated, the hemovac must be removed immediately from the patient to avoid the complications associated with TKA infection. Hence, to be used as a regular source of stem cells, an advanced care protocol for hemovac is required.

TKA is a widely performed surgery and considered to be the gold standard for treatment of late-stage osteoarthritis $(9,10)$. During this surgical procedure, the degenerated bone and cartilage are cut, thereby releasing a large amount of bone marrow components from the bone cutting surface. After the operation, the hemovac line can be inserted intraarticularly to decompress the knee joint thereby preventing hematoma formation. The blood collected in the hemovac contains bone marrow components, which can be used for stem cell research. Most importantly, HVB can be obtained without causing additional pain or harm to the patient. Through the centrifugation of HVB, a sufficient number of cells that have multi-lineage differentiation capacity as stem cells can be obtained. Although the number of cells from HVB and HVBC was very low compared to that from BMA and BMAC, the number of colonies from HVBC and BMAC was not significantly different ( $\left.{ }^{\#}, \mathrm{P}>0.05\right)$. These cells are actual participants in tissue regeneration.

The cells derived from HVB adhered to the culture flask with fibroblast-like morphology, showed multi-lineage differentiation, and expressed stem cell markers (46). CD marker analysis of HVB and HVBC showed over 96\% expression of positive markers (CD29, CD44, CD90, CD105) of MSCs. These results were very similar to those obtained with BMA and BMAC and showed no significant differences.

The multi-differentiation potentials of HVB were evaluated through the culture of cells derived from HVB in osteogenic, adipogenic, and chondrogenic induction medium (46). Alizarin red S (calcium deposit, mineralization) and ALP activity were used for osteogenic differentiation evaluation; BMA showed a higher level of Alizarin red staining, indicating calcium deposit and mineralization. However, the difference in ALP activity between HVB and BMA was not significant. Higher gene expression in BMA was observed for RUNX2, ALP, and osteopontin, but not for osteocalcin.

Peroxisome proliferator-activated receptor- $\gamma(\operatorname{PPAR} \gamma)$ plays an important role in adipogenic differentiation (47). Lipid drop formation was observed using Oil Red $\mathrm{O}$ staining, and $\mathrm{PPAR} \gamma$ and $\mathrm{C} / \mathrm{EBP} \alpha$, as adipocyte differentiation markers, were expressed in HVB and HVBC. The Alcian blue ( $\mathrm{pH} 2.5)$, safranin $\mathrm{O}$, toluidine blue, and type II collagen staining of cells in HVB and HVBC showed chondrogenic differentiation in the form of characteristic matrix synthesis and the formation of cells with surrounding lacuna. Additionally, specific chondrogenesis markers (1) of gene expression, such as type II collagen, SOX9, and aggrecan, were upregulated after 21 days of culture in chondrogenic conditions. The expression of SOX9, aggrecan, and type II collagen did not show any statistically significant difference between HVB and HVBC.

The stem cells from HVB showed characteristic multipotentiality, and a sufficient number of cells could be obtained through centrifugation without any harm or pain to the patients. Through this study, we comprehensively demonstrated that the stem cells from HVB could be potentially used in stem cell research involving musculoskeletal regeneration, including that of cartilage, bone, and fat. Moreover, these stem cells can also be 
explored for their clinical application potential.

After undergoing a TKA operation, patients return to their beds from the surgical theater with a hemovac placed in the knee joint. If the hemovac becomes full of blood, the contents are discarded and new blood begins to fill the hemovac. These first two hemovacs serve as potential sources of stem cells, as after this, the majority of the content will consist of venous blood. The hemovac can hold up to $400 \mathrm{~mL}$ of blood, and the kit that was used in this study processes $40 \mathrm{~mL}$. Hence, theoretically, $800 \mathrm{~mL}$ can be collected from the first and second hemovac, which can be subsequently concentrated using 20 kits. Each kit can produce $4 \mathrm{~mL}$ of $\mathrm{HVBC}$ with counts obtained as follows: white blood cells, $28.36 \pm 19.11 \times 10^{3} / \mu \mathrm{L}$; lymphocytes, $4.87 \pm 3.67 \times 10^{3} / \mu \mathrm{L}$; monocytes, $0.8 \pm 0.74 \times 10^{3} / \mu \mathrm{L}$; platelets, $125.35 \pm 97.78 \times 10^{3} / \mu \mathrm{L}$ (Table 2). It is, therefore, possible to ultimately collect 20 times more than each of these cell counts from a single patient with this method.

HVBC can produce modified autologous stem cells that can be stored for future clinical application. Moreover, if necessary, cells can be cultured to produce enough cells for clinical applications. Therefore, this method might prove to be practical and efficient for clinical trials. For example, if patients suffer from nonunion fractures, osteonecrosis of the femoral head, or osteoarthritis of the knee joint, we can use these banked stem cells as therapeutic options. However, for this kind of clinical application, more laboratory studies are required and clinical trials must be performed.

Recently, studies have been reported on the injection of BMAC into knee joints (48-53). However, bone marrow aspiration must be performed in the operation theater under aseptic conditions with adequate anesthesia according to patient's condition. Further, this procedure is also painful. If HVBC from unilateral TKA can be stored, the cells from this source can be injected into the contralateral knee joints to improve the patient's arthritis-related symptoms.

In this study, we also investigated the optimal time for HVB harvesting. Theoretically, that obtained immediately after surgery is considered of higher quality than that collected later. However, more stem cells were observed in the second HVB aspiration than in the first. There is a possibility that wound irrigation with normal saline prior to completing the operation might dilute the cells from the bone marrow.

To the best of our knowledge, there has been no previous report regarding MSCs derived from HVB. This study demonstrated the morphology, proliferative potential, surface markers, and multi-differentiation ability of the cells obtained from this source, and every aspect was found to be comparable to that of bone marrow-derived stem cells. In conclusion, HVB obtained after total knee replacement can be used as a source of stem cell research or autologous stem cell therapy without the need for invasive and painful bone marrow aspiration procedures.

\section{Acknowledgments}

Funding: This research was supported by the Bio \& Medical Technology Development Program of the National Research Foundation (NRF) funded by the Korean government (MSIT) [NRF-2017M3A9B4028022].

\section{Footnote}

Reporting Checklist: The authors have completed the MDAR checklist. Available at http://dx.doi.org/10.21037/atm-202215

Data Sharing Statement: Available at http://dx.doi. org/10.21037/atm-20-2215

Peer Review File: Available at http://dx.doi.org/10.21037/ atm-20-2215

Conflicts of Interest: All authors have completed the ICMJE uniform disclosure form (available at http://dx.doi. org/10.21037/atm-20-2215). The authors have no conflicts of interest to declare.

Ethical Statement: The authors are accountable for all aspects of the work in ensuring that questions related to the accuracy or integrity of any part of the work are appropriately investigated and resolved. The study was conducted in accordance with the Declaration of Helsinki (as revised in 2013). The study was approved by the Institutional Review Board (UC18DESI0056) and informed consent was obtained from each patient.

Open Access Statement: This is an Open Access article distributed in accordance with the Creative Commons Attribution-NonCommercial-NoDerivs 4.0 International License (CC BY-NC-ND 4.0), which permits the noncommercial replication and distribution of the article with the strict proviso that no changes or edits are made and the original work is properly cited (including links to both the formal publication through the relevant DOI and the license). 
See: https://creativecommons.org/licenses/by-nc-nd/4.0/.

\section{References}

1. Giri TK, Alexander A, Agrawal M, et al. Current status of stem cell therapies in tissue repair and regeneration. Curr Stem Cell Res Ther 2019;14:117-26.

2. Zakrzewski W, Dobrzyński M, Szymonowicz M, et al. Stem cells: past, present, and future. Stem Cell Res Ther 2019;10:68.

3. Méndez-Ferrer S, Scadden DT, Sánchez-Aguilera A. Bone marrow stem cells: current and emerging concepts. Ann N Y Acad Sci 2015;1335:32-44.

4. Wankhade UD, Shen M, Kolhe R, et al. Advances in adipose-derived stem cells isolation, characterization, and application in regenerative tissue engineering. Stem Cells Int 2016;2016:3206807.

5. Baniebrahimi G, Khanmohammadi R, Mir F. Teethderived stem cells: A source for cell therapy. J Cell Physiol 2019;234:2426-35.

6. Caplan AI. Adult mesenchymal stem cells for tissue engineering versus regenerative medicine. J Cell Physiol 2007;213:341-7.

7. Hipp J, Atala A. Sources of stem cells for regenerative medicine. Stem Cell Rev 2008;4:3-11.

8. De Luca M, Aiuti A, Cossu G, et al. Advances in stem cell research and therapeutic development. Nat Cell Biol 2019;21:801-11.

9. Zeni JA, Axe MJ, Snyder-Mackler L. Clinical predictors of elective total joint replacement in persons with endstage knee osteoarthritis. BMC Musculoskelet Disord 2010;11:86.

10. Baier C, Lüring C, Schaumburger J, et al. Assessing patient-oriented results after revision total knee arthroplasty. J Orthop Sci 2013;18:955-61.

11. Jaafar S, Vigdorchik J, Markel DC. Drain technique in elective total joint arthroplasty. Orthopedics 2014;37:37-9.

12. Basaran H, Dasar U, Satılmis B, et al. Usage of Positive pressure Hemovac Drain following Total Knee Arthroplasty: Reduce Blood Lossor Not. SM J Orthop 2016;2:1027.

13. Ayub K, Patterson D, Irani S, et al. Endoscopic ultrasound directed pseudocyst drainage without the use of fluoroscopy: a case series. Gastrointest Endosc 2009;69:S234-S.

14. Gothard D, Dawson J, Oreffo R. Assessing the potential of colony morphology for dissecting the CFU-F population from human bone marrow stromal cells. Cell Tissue Res
2013;352:237-47.

15. Puchtler H, Meloan SN, Terry MS. On the history and mechanism of alizarin and alizarin red $\mathrm{S}$ stains for calcium. J Histochem Cytochem 1969;17:110-24.

16. Hoemann C, El-Gabalawy H, McKee M. In vitro osteogenesis assays: influence of the primary cell source on alkaline phosphatase activity and mineralization. Pathologie Biologie 2009;57:318-23.

17. Little CJ, Bawolin NK, Chen X. Mechanical properties of natural cartilage and tissue-engineered constructs. Tissue Eng Part B Rev 2011;17:213-27.

18. Kuhne M, John T, El-Sayed K, et al. Characterization of auricular chondrocytes and auricular/articular chondrocyte co-cultures in terms of an application in articular cartilage repair. Int J Mol Med 2010;25:701-8.

19. Mohsin S, Houser SR. Cortical Bone Derived Stem Cells for Cardiac Wound Healing. Korean Circ J 2019;49:314-25.

20. Jin H, Bae Y, Kim M, et al. Comparative analysis of human mesenchymal stem cells from bone marrow, adipose tissue, and umbilical cord blood as sources of cell therapy. Int J Mol Sci 2013;14:17986-8001.

21. Khan WS, To K, Zhang B, et al. Synovium-Derived Mesenchymal Stem Cell Transplantation in Cartilage Regeneration: A PRISMA Review of in vivo Studies. Front Bioeng Biotechnol 2019;7:314.

22. Zupan J, Drobnič M, Stražar K. Synovium-Derived Mesenchymal Stem/Stromal Cells and their Promise for Cartilage Regeneration. Adv Exp Med Biol 2020;1212:87-106.

23. Si Z, Wang X, Sun C, et al. Adipose-derived stem cells: Sources, potency, and implications for regenerative therapies. Biomed Pharmacother 2019;114:108765.

24. Hoffmann A, Floerkemeier T, Melzer C, et al. Comparison of in vitro-cultivation of human mesenchymal stroma/ stem cells derived from bone marrow and umbilical cord. J Tissue Eng Regen Med 2017;11:2565-81.

25. Han Y, Li X, Zhang Y, et al. Mesenchymal stem cells for regenerative medicine. Cells 2019;8:886.

26. Rajabzadeh N, Fathi E, Farahzadi R. Stem cell-based regenerative medicine. Stem Cell Investig 2019;6:19.

27. Trohatou O, Roubelakis MG. Mesenchymal stem/stromal cells in regenerative medicine: past, present, and future. Cell Reprogram 2017;19:217-24.

28. Rothrauff BB, Pirosa A, Lin H, et al. Stem Cell Therapy for Musculoskeletal Diseases. Available online: https://www.sciencedirect.com/science/article/pii/ B9780128098806000540 
29. Piuzzi NS, Ng M, Chughtai M, et al. Accelerated Growth of Cellular Therapy Trials in Musculoskeletal Disorders: An Analysis of the NIH Clinical Trials Data Bank. Orthopedics 2019;42:e144-e150.

30. Robinson PG, Murray IR, West CC, et al. Reporting of Mesenchymal Stem Cell Preparation Protocols and Composition: A Systematic Review of the Clinical Orthopaedic Literature. Am J Sports Med 2019;47:991-1000.

31. Angadi DS, Macdonald H, Atwal N. Autologous cellfree serum preparations in the management of knee osteoarthritis: what is the current clinical evidence? Knee Surg Relat Res 2020;32:16.

32. Berebichez-Fridman R, Gómez-García R, GranadosMontiel J, et al. The Holy Grail of Orthopedic Surgery: Mesenchymal Stem Cells-Their Current Uses and Potential Applications. Stem Cells Int 2017;2017:2638305.

33. Cheng HY, Ghetu N, Wallace C, et al. The impact of mesenchymal stem cell source on proliferation, differentiation, immunomodulation and therapeutic efficacy. J Stem Cell Res Ther 2014;4:1-8.

34. Cagliani J, Grande D, Molmenti EP, et al. Immunomodulation by mesenchymal stromal cells and their clinical applications. J Stem Cell Regen Biol 2017;3:10.15436/2471-0598.17.022.

35. Kern S, Eichler H, Stoeve J, et al. Comparative analysis of mesenchymal stem cells from bone marrow, umbilical cord blood, or adipose tissue. Stem Cells 2006;24:1294-301.

36. Choudhery MS, Badowski M, Muise A, et al. Donor age negatively impacts adipose tissue-derived mesenchymal stem cell expansion and differentiation. J Transl Med 2014;12:8.

37. Gang EJ, Hong SH, Jeong JA, et al. In vitro mesengenic potential of human umbilical cord blood-derived mesenchymal stem cells. Biochem Biophys Res Commun 2004;321:102-8.

38. Lotfy A, El-Sherbiny YM, Cuthbert R, et al. Comparative study of biological characteristics of mesenchymal stem cells isolated from mouse bone marrow and peripheral blood. Biomed Rep 2019;11:165-70.

39. He Q, Wan C, Li G. Concise review: multipotent mesenchymal stromal cells in blood. Stem Cells 2007;25:69-77.

40. Koerner J, Nesic D, Romero JD, et al. Equine peripheral blood-derived progenitors in comparison to bone marrow-derived mesenchymal stem cells. Stem Cells 2006;24:1613-9.

41. Zvaifler NJ, Marinova-Mutafchieva L, Adams G, et al.
Mesenchymal precursor cells in the blood of normal individuals. Arthritis Res 2000;2:477-88.

42. Fu WL, Zhang JY, Fu X, et al. Comparative study of the biological characteristics of mesenchymal stem cells from bone marrow and peripheral blood of rats. Tissue Eng Part A 2012;18:1793-803.

43. Longhini ALF, Salazar TE, Vieira C, et al. Peripheral blood-derived mesenchymal stem cells demonstrate immunomodulatory potential for therapeutic use in horses. PLoS One 2019;14:e0212642.

44. Li S, Huang KJ, Wu JC, et al. Peripheral blood-derived mesenchymal stem cells: candidate cells responsible for healing critical-sized calvarial bone defects. Stem Cells Transl Med 2015;4:359-68.

45. Fu Q, Tang NN, Zhang Q, et al. Preclinical Study of Cell Therapy for Osteonecrosis of the Femoral Head with Allogenic Peripheral Blood-Derived Mesenchymal Stem Cells. Yonsei Med J 2016;57:1006-15.

46. Dominici M, Le Blanc K, Mueller I, et al. Minimal criteria for defining multipotent mesenchymal stromal cells. The International Society for Cellular Therapy position statement. Cytotherapy 2006;8:315-7.

47. Rosen ED, Spiegelman BM. PPARgamma : a nuclear regulator of metabolism, differentiation, and cell growth. J Biol Chem 2001;276:37731-4.

48. Goncars V, Kalnberzs K, Jakobsons E, et al. Treatment of Knee Osteoarthritis with Bone Marrow-Derived Mononuclear Cell Injection: 12-Month Follow-up. Cartilage 2019;10:26-35.

49. Mautner K, Carr D, Whitley J, et al. Allogeneic Versus Autologous Injectable Mesenchymal Stem Cells for Knee Osteoarthritis: Review and Current Status. Tech Orthop 2019;34:244-56.

50. Kim SH, Ha CW, Park YB, et al. Intra-articular injection of mesenchymal stem cells for clinical outcomes and cartilage repair in osteoarthritis of the knee: a metaanalysis of randomized controlled trials. Arch Orthop Trauma Surg 2019;139:971-80.

51. Lamo-Espinosa JM, Mora G, Blanco JF, et al. Intraarticular injection of two different doses of autologous bone marrow mesenchymal stem cells versus hyaluronic acid in the treatment of knee osteoarthritis: multicenter randomized controlled clinical trial (phase I/II). J Transl Med 2016;14:246.

52. Jo CH, Chai JW, Jeong EC, et al. Intra-articular injection of mesenchymal stem cells for the treatment of osteoarthritis of the knee: a 2-year follow-up study. Am J Sports Med 2017;45:2774-83. 
53. Emadedin M, Labibzadeh N, Liastani MG, et al. Intraarticular implantation of autologous bone marrow-derived mesenchymal stromal cells to treat knee osteoarthritis: a

Cite this article as: Kim SA, Park HY, Shin YW, Go EJ, Kim YJ, Kim YC, Shetty AA, Kim SJ. Hemovac blood after total knee arthroplasty as a source of stem cells. Ann Transl Med 2020;8(21):1406. doi: 10.21037/atm-20-2215 randomized, triple-blind, placebo-controlled phase $1 / 2$ clinical trial. Cytotherapy 2018;20:1238-46. 